\title{
1 Unravelling partial melt distribution in the oceanic low velocity zone
}

3

4

$5 \quad{ }^{1}$ Centre de recherche sur les Ions, les Matériaux et la Photonique (CIMAP), Normandie Université,

6 ENSICAEN, UNICAEN, CEA, CNRS, Caen, France

7 22aboratoire Magmas et Volcans (LMV), Université Clermont Auvergne, CNRS, IRD, OPGC,

8 Clermont-Ferrand, France

$9{ }^{3}$ Deep and Early Earth Processes Research Group (DEEP), Department of Geology, University of Johannesburg, Auckland Park, South Africa

11

${ }^{4}$ Institut des Sciences de la Terre d'Orléans (ISTO), Université d'Orléans, CNRS, BRGM, Orléans,

12

France

13

14

*Correspondence to: gardes@ganil.fr

15

Current address: Institute for Mineralogy, University of Münster, Münster, Germany
17

18

19

20

21

22 


\section{Abstract}

The widespread low seismic velocity zone (LVZ) in the shallow oceanic mantle has long been debated in terms of mantle melting. At $\mathrm{LVZ}$ depths, volatiles $\left(\mathrm{CO}_{2}\right.$ and $\left.\mathrm{H}_{2} \mathrm{O}\right)$ are present in minute amounts, which implies mantle incipient melting down to below $1000^{\circ} \mathrm{C}$ with the production of minute amounts of volatile-rich melt, well below 1 vol.\%. However, melt compositions and distributions in the incipient melting regime have only been inferred from experiments departing from actual mantle conditions. Here, we experimentally reproduce incipient melting by re-equilibrating a naturally $\mathrm{CO}_{2^{-}}$and $\mathrm{H}_{2} \mathrm{O}-$ bearing mantle rock at mantle temperatures and pressure. By using cutting-edge microscopy characterizations, we evidence that minute amounts of volatile-rich melts fully interconnect in mantle rocks down to lithospheric temperatures, enabling thus the modification of geophysical signals from the mantle. These findings and the correspondence of the domain of local, sharp drops in shear wave velocity (Vs) with the domain of $\left(\mathrm{CO}_{2}+\mathrm{H}_{2} \mathrm{O}\right)$-melting in the LVZ strongly supports that these geophysical anomalies relate to mantle melting. Geophysical surveys image in situ the very low and highly heterogeneous distribution of melt in the mantle generated by the very low and highly heterogeneous distribution of volatiles probed by surficial geochemical surveys. The global-scale geophysical signature of the LVZ appears mainly unaffected because the average background melt fraction is very low, estimated at $\sim 0.03-0.05$ vol.\% melt. However, enhanced geophysical signals arise from sporadic, localized areas where melt fraction is increased, such as the $\sim 0.2$ vol.\% melt estimated for detecting sharp Vs drops using SS precursors. In-depth deciphering of the dynamics of melt and volatiles in the LVZ calls for investigations on the seismic velocity, permeability and rheology of partially molten mantle rocks covering the diversity of mantle melt compositions, fractions and temperatures.

\section{Keywords}

Mantle incipient melting, Volatile-rich melt interconnection in mantle rocks, Low Velocity Zone, Distribution and dynamics of volatiles and melt in the upper mantle 


\section{Introduction}

Both $\mathrm{CO}_{2}$ and $\mathrm{H}_{2} \mathrm{O}$ are present in the upper mantle, though in minute amounts and heterogeneously distributed (Le Voyer et al., 2017). Melting is thus expected to occur in a vast region extending from young and hot to old and cold oceanic mantle (Fig. 1), and to generate volatile-rich melts with low and heterogeneous volume fractions correlated to the low and heterogeneous volatile contents (Wallace and Green, 1988; Hirano et al., 2006; Hirschmann, 2010; Dasgupta et al., 2013; Massuyeau et al., 2015; Machida et al., 2017; Gaillard et al., 2019). To date, melting experiments on mantle rocks with very small amounts of both $\mathrm{CO}_{2}$ and $\mathrm{H}_{2} \mathrm{O}(<1000$ wt. ppm) producing very small fractions $(<1$ vol.\%) of $\left(\mathrm{CO}_{2}+\mathrm{H}_{2} \mathrm{O}\right)$-rich incipient melts down to lithospheric temperatures have never been investigated. This raises important issues. First, melt compositions and fractions produced in the incipient melting regime may differ from that inferred from conventional experiments where $\mathrm{CO}_{2}$ and $\mathrm{H}_{2} \mathrm{O}$ are added in amounts greatly exceeding those present in the mantle. Second, the intergranular distribution of small fractions of incipient melts in mantle rocks is unknown. Those melts have to form interconnected networks to enable significant modifications of mantle properties in the LVZ. Among those are seismic velocity lowering (Faul et al., 2004; Takei and Holtzman, 2009a, 2009b; Rychert and Shearer, 2011; Schmerr, 2012; Chantel et al., 2016; Takei, 2017; Tharimena et al., 2017), electrical conductivity increase (Naif et al., 2013; Sifré et al., 2014; Laumonier et al., 2017), and steady-state viscosity lowering (Hirth and Kohlstedt 1995a, 1995b, 2003; Takei and Holtzman, 2009a, 2009b; Holtzman, 2016). Our knowledge about melt interconnection in the upper mantle remained far too partial as it involves experiments at too high temperatures, too large melt fractions, and in simplified petrological systems (Minarik and Watson, 1995; Faul et al., 2004; ten Grotenhuis et al., 2005; Yoshino et al., 2009, 2010; Zhu et al., 2011; Miller et al., 2014; Mu and Faul, 2016, Laumonier et al., 2017). Unravelling melt interconnection at actual mantle conditions require investigations down to lithospheric temperatures $\left(\sim 1000^{\circ} \mathrm{C}\right)$ and on minute fractions (< 1 vol.\%) of $\left(\mathrm{CO}_{2}+\mathrm{H}_{2} \mathrm{O}\right)$-rich melts.

Here we report extensive investigations on experimental reproductions of actual mantle melting. Our novel approach consists in re-equilibrating a volatile-bearing mantle xenolith at mantle-relevant conditions (Fig. 1). This starting material naturally contains minute amounts of volatiles, i.e. $500 \pm 50$ 
wt.ppm $\mathrm{CO}_{2}$ and $630 \pm 210$ wt.ppm $\mathrm{H}_{2} \mathrm{O}$. It was used to perform high pressure and temperature experiments in the $\left(\mathrm{CO}_{2}+\mathrm{H}_{2} \mathrm{O}\right)$-assisted melting domain, at conditions corresponding to $\sim 100 \mathrm{~km}$ depth beneath young and hot to old and cold oceanic lithospheres, where both volatile-free-melting and $\mathrm{H}_{2} \mathrm{O}-$ only-assisted melting are not possible (Fig, 1). We directly evidence that minute amounts of both $\mathrm{CO}_{2}$ and $\mathrm{H}_{2} \mathrm{O}$ do generate minute amounts of interconnected, $\left(\mathrm{CO}_{2}+\mathrm{H}_{2} \mathrm{O}\right)$-rich melts in mantle rocks down to lithospheric temperatures. The distribution of melt and volatile and its relationship with geophysical signals in the LVZ are finally discussed.

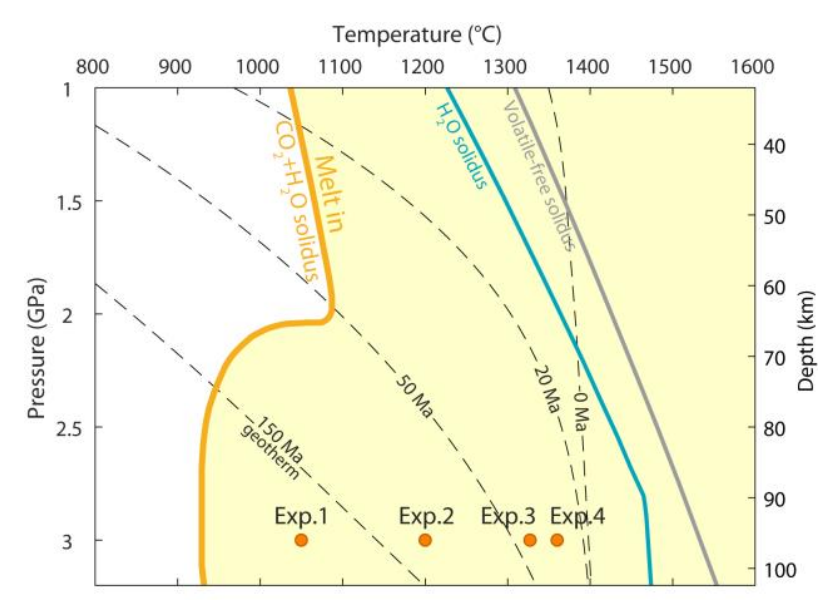

Fig. 1. Incipient melting at shallow mantle temperatures and pressure. Present experiments investigate the domain of $\left(\mathrm{CO}_{2}+\mathrm{H}_{2} \mathrm{O}\right.$ )-assisted melting (Wallace and Green, 1988) which covers young and hot to old and cold oceanic mantle, down to temperatures where both volatile-free-melting and $\mathrm{H}_{2} \mathrm{O}$-only-melting (200 wt.ppm) (Sarafian et al., 2017) are precluded. Mantle thermal structure is G13R1350 model with $1350^{\circ} \mathrm{C}$ potential temperature from Grose and Afonso (2013).

\section{Materials and methods}

\subsection{Starting material}

The mantle xenolith is a spinel-peridotite sampled at Lanzarote (Canary Islands). A large piece of the xenolith was crushed in agate mortar and the powder remained stored in desiccator prior to analysis and experiments. Bulk rock composition was measured twice using inductively coupled plasma atomic emission spectroscopy (ICP-AES) at LMV. $\mathrm{CO}_{2}$ and $\mathrm{H}_{2} \mathrm{O}$ contents were measured three times on 
samples of $1 \mathrm{mg}$ each using organic elemental analyser at LMV. Averages of these measurements, with uncertainties given as twice the standard deviation of the mean (95\% confidence interval), are reported in Table 1. Note that the low values of $630 \pm 210$ wt.ppm $\mathrm{H}_{2} \mathrm{O}$ and $500 \pm 50$ wt.ppm $\mathrm{CO}_{2}$ evidence the xenolith did not experience significant weathering at the surface.

\subsection{High pressure and temperature experiments}

The xenolith powder was loaded in 3-mm diameter $\mathrm{Au}_{80} \mathrm{Pd}_{20}$ capsules and welded shut with no additional dopant. High pressure and temperature experiments were performed at LMV using pistoncylinder apparatus with conventional 1/2-inch assembly made of $\mathrm{NaCl}$ and pyrex glass as pressure medium and thermal insulator, respectively. The temperature was generated by a graphite furnace and monitored with a C-type thermocouple placed at about $0.5 \mathrm{~mm}$ above the capsule. Experiments started with the pressurization of the assembly to $1 \mathrm{GPa}$ followed by heating to $650^{\circ} \mathrm{C}$ at a rate of $60^{\circ} \mathrm{C} / \mathrm{min}$. The assembly was then pressurized to $3 \mathrm{GPa}$, before heating to target temperatures: $1050,1200,1327$ and $1360^{\circ} \mathrm{C}$ for Exp. 1, 2, 3 and 4, respectively (Table 2). Uncertainties on temperature and pressure are within $20^{\circ} \mathrm{C}$ and $0.3 \mathrm{GPa}$, respectively. At the end of the experiment, power was switched off, resulting in a cooling rate of $\sim 100^{\circ} \mathrm{C} / \mathrm{s}$, and then slowly decompressed to room pressure. Recovered capsules were sawed and one half was embedded in epoxy resin for mechanical polishing down to $1 / 4 \mu \mathrm{m}$ using diamond abrasives. Sawing and polishing were performed using ethanol as lubricant; no water was used to avoid carbonate dissolution (Wallace and Green, 1988). The samples were prepared for electron microscopy by coating the surfaces with a few tens nm layer of carbon using a carbon coater.

\subsection{Electron microscopy characterizations}

The characterization of the experiments was performed using the scanning electron microscope coupled with focused Ga-ion beam (SEM-FIB) of CIMAP, equipped with an energy-dispersive X-ray spectroscopy detector (EDS) and a scanning transmission electron microscopy detector.

Melt fraction, grain size and grain boundary wetness, i.e. the fraction of grain surface wetted by melt, were determined on images acquired at the centre of the capsules. Acquisitions were performed at $5 \mathrm{kV}$ and 0.05-3.2 nA in backscattered electron mode using high definition, $3072 \times 2048$ - or $6144 \times 4096$-pixel 
images with pixel sizes of 8 to $34 \mathrm{~nm}$ (Fig. 2). Combining these resolutions together with large enough fields of view mostly required image mappings of the regions of interest. Because of a poorer quality of mechanical polishing, the images of Exp. 1 were acquired on two large ion-beam polished sections extracted perpendicular to sample surface (Fig. 2). Mineralogical assemblage was identified from EDS maps at 10-15 kV and 3.2-13 nA, using Aztec EDS acquisition and data processing software by Oxford Instruments (Fig. 2, Table 2).

High magnification images of melt areas were acquired in transmission mode at $30 \mathrm{kV}$ and $0.1 \mathrm{nA}$ on 100-200 nm-thick, electron-transparent ion-thinned sections extracted perpendicular to the surface at the centre of the capsules (Fig. 3). The chemical composition of the melt in the samples was based on the EDS mapping of the electron-transparent thin sections in transmission mode at $30 \mathrm{kV}$ and $0.8-3.2$ nA (Figs. 3-4; Figs. S1-S2). This was necessary since using conventional SEM-EDS mapping of bulk sample surface, (i) carbon signals from the carbon layer deposited onto sample surface would have interfered with those from melt, and (ii) signals from surrounding grains would have interfered with those from melt because of too large X-ray generation volumes. As there are only a few melt occurrences per thin section, 28 thin sections were extracted over the four samples in order to improve statistics.

These high magnification images were also used to measure the apparent contact angles at the junctions of melt with the various mineral phases of the samples (Fig. 5). The contact angles reported in Table 2 are the medians of these measurements (Laporte and Watson, 1995), and associated uncertainties correspond to twice the standard deviation of the mean (95\% confidence intervals).

Olivine iron number at the vicinity of capsule walls was investigated from EDS maps at $15 \mathrm{kV}$ and 6.4$13 \mathrm{nA}$. The maps were decomposed into series of $30 \mu \mathrm{m}$-wide rectangles with long side $(170-260 \mu \mathrm{m})$ parallel to capsule wall. The profiles reported in Fig. 5 correspond to the olivine iron number in each rectangle, after calibrating the EDS signals on olivine standard.

The 3D distribution of melt was investigated by excavating small volumes in the centre of capsules using serial FIB sectioning-electron imaging (see Cocoo et al., 2013 for further details on the technique). We used $30 \mathrm{kV}$ and $0.43-2.5 \mathrm{nA} \mathrm{Ga}$-ions for producing series of cross sections every 27 to $67 \mathrm{~nm}$, and 
149 pixel sizes of 4.5 to $14 \mathrm{~nm}$. Each volume involved 98 to 172 images (Fig. 5, Videos S1-S4).

150 Segmentation of the images was performed using the hand tracing tools of Fiji software (Schindelin et 151 al., 2012). This was especially required for precise contouring of melt areas whose distribution is mostly 152 sub-micrometric. Melt fraction, grain size and grain boundary wetness were calculated as in Mu and 153 Faul (2016). Corresponding uncertainties are given as twice the standard deviation of the mean (95\% confidence intervals) (Table 2). 3D images of melt were generated from the stacks of binary images produced by serial FIB sectioning-electron imaging using the 3D viewer plugin of Fiji (Fig. 5, Videos

$156 \mathrm{~S} 1-\mathrm{S} 4)$. Melt interconnection is defined as the proportion of melt residing in the largest interconnected 157 network of melt. confidence intervals.

\begin{tabular}{ll}
\hline $\mathrm{SiO}_{2}$ & $42.8 \pm 0.2$ \\
$\mathrm{TiO}_{2}$ & $0.013 \pm 0.017$ \\
$\mathrm{Al}_{2} \mathrm{O}_{3}$ & $0.80 \pm 0.37$ \\
$\mathrm{Cr}_{2} \mathrm{O}_{3}$ & $0.33 \pm 0.24$ \\
$\mathrm{FeO}_{t}$ & $7.58 \pm 0.04$ \\
$\mathrm{NiO}$ & $0.36 \pm 0.16$ \\
$\mathrm{MnO}$ & $0.120 \pm 0.003$ \\
$\mathrm{MgO}$ & $47.2 \pm 0.9$ \\
$\mathrm{CaO}$ & $0.71 \pm 0.17$ \\
$\mathrm{~K}_{2} \mathrm{O}$ & $0.050 \pm 0.097$ \\
$\mathrm{Na}_{2} \mathrm{O}$ & $0.040 \pm 0.010$ \\
$\mathrm{CO}_{2}$ & $0.050 \pm 0.005$ \\
$\mathrm{H}_{2} \mathrm{O}$ & $0.063 \pm 0.021$
\end{tabular}



orthopyroxene, $\mathrm{Cpx}=$ clinopyroxene, $\mathrm{Spl}=$ spinel, $\mathrm{Grt}=$ garnet, $\mathrm{Phl}=$ phlogopite.

\begin{tabular}{|c|c|c|c|c|}
\hline Sample & Exp. 1 & Exp. 2 & Exp. 3 & Exp. 4 \\
\hline $\mathrm{T}\left({ }^{\circ} \mathrm{C}\right)$ & 1050 & 1200 & 1327 & 1360 \\
\hline $\mathrm{P}(\mathrm{GPa})$ & 3 & 3 & 3 & 3 \\
\hline Run duration (h) & 192 & 192 & 96 & 63.5 \\
\hline Assemblage & $\mathrm{Ol}+\mathrm{Opx}+\mathrm{Cpx}+\mathrm{Grt}+\mathrm{Phl}+\mathrm{Melt}$ & $\mathrm{Ol}+\mathrm{Opx}+\mathrm{Cpx}+\mathrm{Grt}+\mathrm{Melt}$ & $\mathrm{Ol}+\mathrm{Opx}+\mathrm{Cpx}+\mathrm{Grt}+\mathrm{Melt}$ & $\mathrm{Ol}+\mathrm{Opx}+\mathrm{Cpx}+\mathrm{Melt}$ \\
\hline Melt fraction (vol.\%) & $0.11 \pm 0.05$ & $0.16 \pm 0.02$ & $0.15 \pm 0.02$ & $1.5 \pm 0.5$ \\
\hline Melt interconnection (\%) & $\sim 100$ & $\sim 100$ & $\sim 100$ & $\sim 100$ \\
\hline Contact angle $\left({ }^{\circ}\right)$ & $32.5 \pm 6.0$ & $30.7 \pm 4.0$ & $36.3 \pm 4.0$ & $26.3 \pm 4.5$ \\
\hline Gain boundary wetness (\%) & $4.4 \pm 1.4$ & $5.4 \pm 1.0$ & $9.6 \pm 2.1$ & $20.9 \pm 5.0$ \\
\hline Grain size $(\mu \mathrm{m})$ & $4.9 \pm 0.9$ & $4.6 \pm 0.9$ & $6.4 \pm 1.0$ & $10.3 \pm 1.8$ \\
\hline \multicolumn{5}{|l|}{ Melt chemistry (wt.\%) } \\
\hline $\mathrm{SiO}_{2}$ & $3.3 \pm 2.4$ & $9.6 \pm 4.4$ & $9.8 \pm 4.8$ & $45.2 \pm 9.5$ \\
\hline $\mathrm{Al}_{2} \mathrm{O}_{3}$ & $0.69 \pm 0.49$ & $1.4 \pm 0.7$ & $1.5 \pm 1.0$ & $11.0 \pm 4.0$ \\
\hline $\mathrm{FeO}$ & $4.5 \pm 1.9$ & $3.1 \pm 1.2$ & $2.4 \pm 0.9$ & $6.0 \pm 2.3$ \\
\hline $\mathrm{MgO}$ & $29.2 \pm 9.3$ & $19.1 \pm 6.3$ & $18.2 \pm 6.0$ & $12.9 \pm 4.6$ \\
\hline $\mathrm{CaO}$ & $11.8 \pm 6.8$ & $20.4 \pm 6.6$ & $17.6 \pm 5.9$ & $9.9 \pm 3.6$ \\
\hline $\mathrm{K}_{2} \mathrm{O}$ & $1.7 \pm 3.0$ & $1.9 \pm 2.1$ & $2.6 \pm 2.8$ & $2.0 \pm 1.1$ \\
\hline $\mathrm{Na}_{2} \mathrm{O}$ & $0.60 \pm 1.12$ & $0.58 \pm 0.82$ & $1.0 \pm 1.1$ & $3.3 \pm 1.3$ \\
\hline $\mathrm{CO}_{2}$ & $36.9 \pm 9.8$ & $34.5 \pm 8.6$ & $34.6 \pm 8.4$ & $7.0 \pm 3.6$ \\
\hline $\mathrm{H}_{2} \mathrm{O}$ & $11.4 \pm 8.0$ & $9.4 \pm 3.2$ & $12.4 \pm 3.8$ & $2.6 \pm 0.9$ \\
\hline
\end{tabular}

167

\section{Results}

\subsection{Phase assemblage, melt chemistry and melt volume fraction}

All samples contain small amounts of volatile-rich melt after experiments. Assemblages are olivine +

$172+$ melt (Fig. 2, Table 2). Melt does not quench as a glass at the end of the experiments (e.g. Wallace and

173 Green, 1988), but results in quenched nano-crystals with 5-30 vol.\% of pores most likely filled with a

$174 \mathrm{~K}_{2} \mathrm{O}-\mathrm{Na}_{2} \mathrm{O}-\mathrm{CO}_{2}-\mathrm{H}_{2} \mathrm{O}$-bearing fluid phase that was removed during sample preparation (Fig. 3, Figs. S1-

175 S2). Melt crystallization sequence during cooling of the experiments is (i) garnet between 1360 and $1327^{\circ} \mathrm{C}$, (ii) phlogopite between 1200 and $1050^{\circ} \mathrm{C}$, and (iii) carbonate (+fluid) below $1050^{\circ} \mathrm{C}$. This is consistent with the evolution of phase assemblage; starting from minute amount of carbonatitic melt at 

occurs between 1327 and $1360^{\circ} \mathrm{C}$.

The melt compositions reported in Fig. 4 and Table 2 combine the composition measured on quenched nano-crystals and that inferred for the fluid in pores (see calculation details in Supplementary Material). The rather large uncertainties partly result from the fact that melt distribution is mostly sub-micrometric, requiring unconventional characterizations in transmission electron mode on electron-transparent cross sections (Fig. 3, Fig. S1-S2). From $1050^{\circ} \mathrm{C}$ to $1327^{\circ} \mathrm{C}, 0.11-0.15$ vol. $\%$ of carbonated melt is produced, with $\mathrm{CO}_{2}, \mathrm{H}_{2} \mathrm{O}$ and $\mathrm{SiO}_{2}$ concentrations of about 35, 10 and 3-10 wt.\%, respectively. A transition occurs before $1360^{\circ} \mathrm{C}$ where melt fraction shifts to $1.5 \mathrm{vol} . \%$ and melt composition becomes mainly silicated, with $\mathrm{CO}_{2}, \mathrm{H}_{2} \mathrm{O}$ and $\mathrm{SiO}_{2}$ concentrations of about 7,3 and 45 wt.\%, respectively. These melt compositions, and their evolution with temperature, are in line with previous volatile-doped experiments with much higher melt fractions (Fig. 4).

\subsection{Melt distribution and interconnection}

Melt phase is virtually fully interconnected in all the samples (Fig. 5, Videos S1-S4, Table 2). (i) Highresolution 3D reconstructions evidence melt mainly forms tubule networks along grain edges, and tends to spread along grain boundaries in the sample with the highest melt fraction (Fig. 5). Grain boundary wetness range from about 5-10\% in samples with 0.1-0.15 vol.\% melt (Exp. 1,2 and 3) to about 20\% in the sample with 1.5 vol.\% melt (Exp. 4) (Table 2). (ii) Measurements of the apparent contact angles at the junctions of melt with the various mineral phases yield median values ranging around $30^{\circ}$ in all samples (Fig. 5, Table 2), theoretically implying full melt interconnection (von Bargen and Waff, 1986). (iii) Long range interconnection of melt is confirmed by a minor loss of iron over a few hundreds of micrometres from olivine crystals to capsule walls, though made of Au-Pd (iron depletion reaches 5$10 \%$ at the interface with capsule walls) (Fig. 5). This loss occurred via diffusion in the melt network since iron diffusion in melt-free aggregate would have been limited to much shorter distances (Fig. 5, Supplementary Material). It should be recalled that melt analyses, as well as the other measurements, were performed in the centre of the $3 \mathrm{~mm}$ diameter capsules and thus were virtually unaffected by such 
204 a minor iron loss restricted to the vicinity of capsule walls. Indeed, no significant differences can be 205 found between the iron melt contents in our samples and those from literature (Fig. 4). 

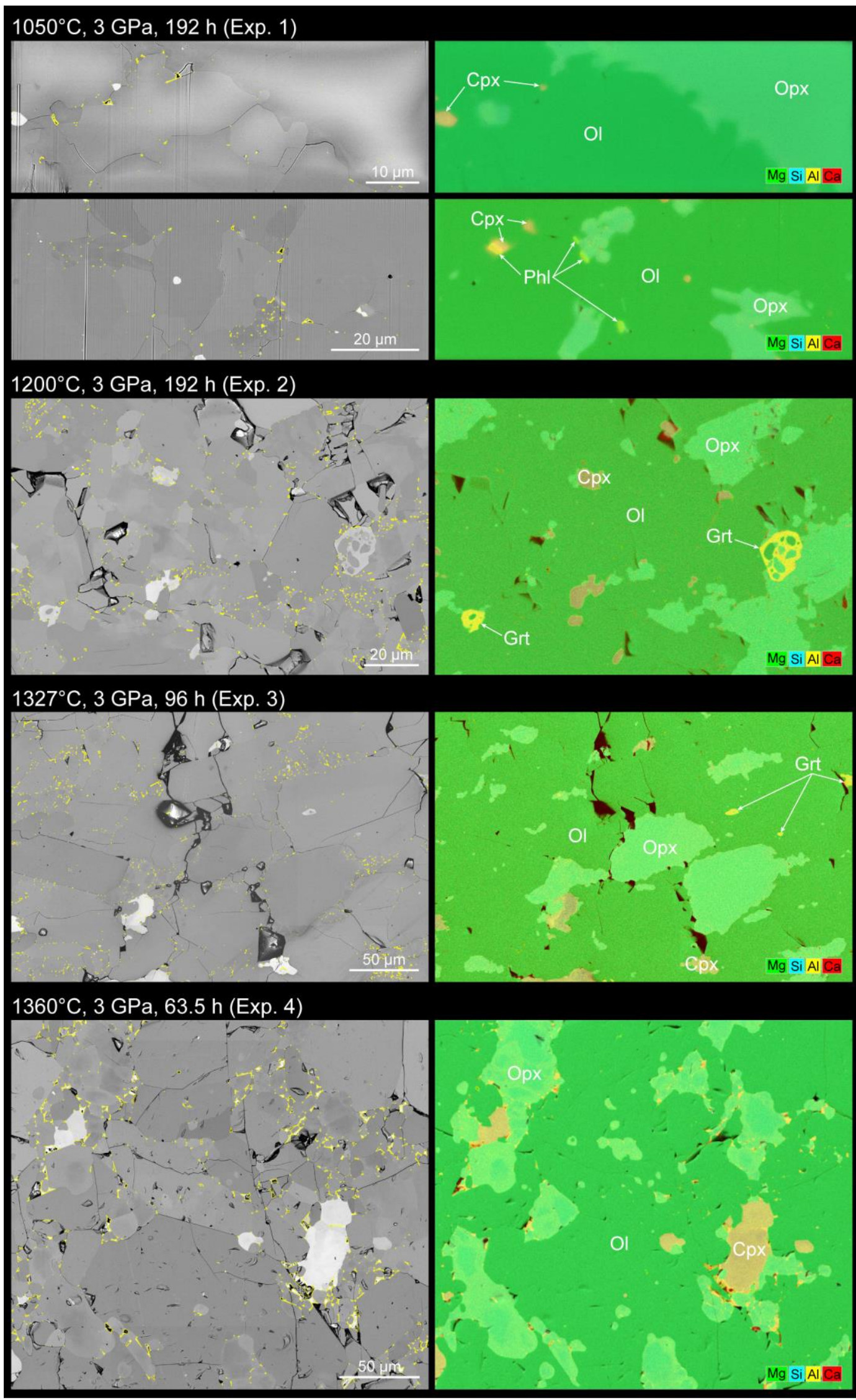

211 Fig. 2. Broad image and chemical mappings of a $\left(\mathrm{CO}_{2}+\mathrm{H}_{2} \mathrm{O}\right)$-bearing mantle rock experimentally re-equilibrated at shallow 212 mantle temperatures and pressure. Left panels, backscattered electron image mappings on which melt contours are reported in 

calcium EDS maps. $\mathrm{Ol}=$ olivine, $\mathrm{Opx}=$ orthopyroxene, $\mathrm{Cpx}=$ clinopyroxene, $\mathrm{Grt}=$ garnet, $\mathrm{Phl}=$ phlogopite .

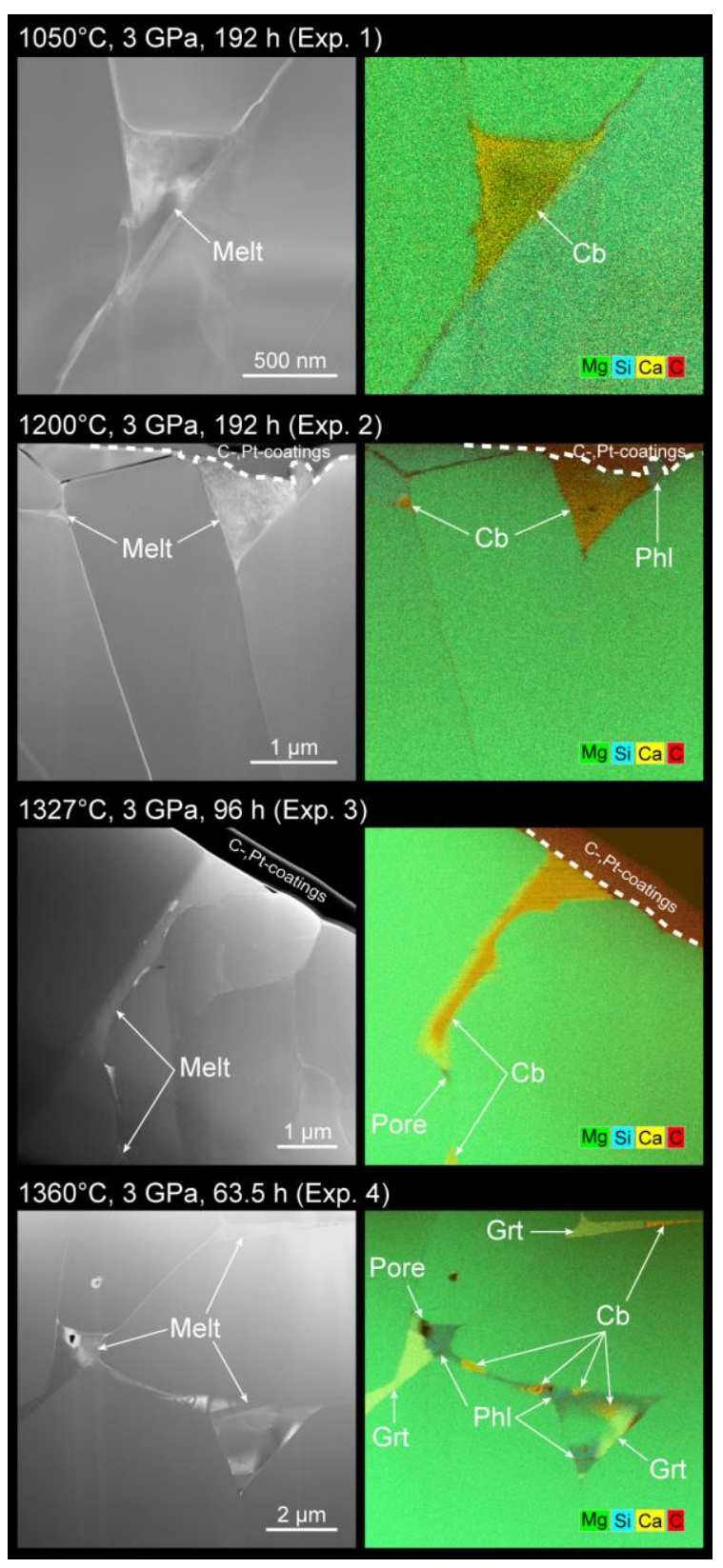

217 Fig. 3. High magnification imaging and chemical mappings of incipient melts in a $\left(\mathrm{CO}_{2}+\mathrm{H}_{2} \mathrm{O}\right)$-bearing mantle rock experimentally re-equilibrated at shallow mantle temperatures and pressure. Left panels, transmission electron imaging of electron-transparent thin sections extracted perpendicular to sample surfaces. Right panels, corresponding chemical mappings reported as superposition of magnesium, silicon, calcium and carbon EDS maps. Note that the melt does not quench as glass at the end of the experiments but results in quenched nano-crystals and fluid-filled pores $(\mathrm{Cb}=$ carbonate, $\mathrm{Phl}=$ phlogopite, Grt $=$ garnet $)$ 

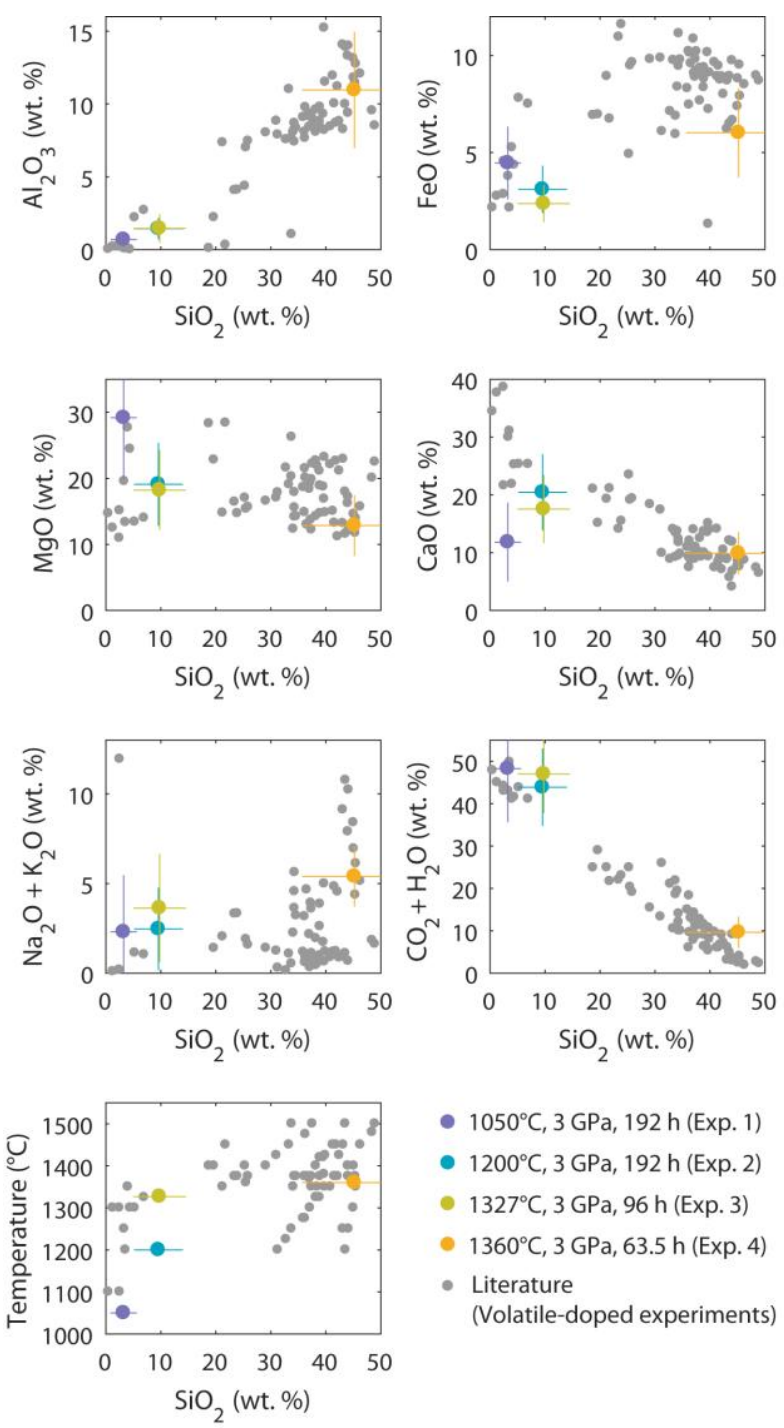

- $1050^{\circ} \mathrm{C}, 3 \mathrm{GPa}, 192 \mathrm{~h}$ (Exp. 1)

- $1200^{\circ} \mathrm{C}, 3 \mathrm{GPa}, 192 \mathrm{~h}$ (Exp. 2)

- $1327^{\circ} \mathrm{C}, 3 \mathrm{GPa}, 96 \mathrm{~h}$ (Exp. 3)

- $1360^{\circ} \mathrm{C}, 3 \mathrm{GPa}, 63.5 \mathrm{~h}$ (Exp. 4)

- Literature

(Volatile-doped experiments)

Fig. 4. Composition of incipient melts in a $\left(\mathrm{CO}_{2}+\mathrm{H}_{2} \mathrm{O}\right)$-bearing mantle rock experimentally re-equilibrated at shallow mantle temperatures and pressure. Literature data regroup experiments producing volatile-bearing melts $\left(\mathrm{CO}_{2}\right.$ and/or $\left.\mathrm{H}_{2} \mathrm{O}\right)$ at comparable pressures $\left(2.5-3.5 \mathrm{GPa}\right.$ ) and temperatures (up to $1500^{\circ} \mathrm{C}$ ), in at least $\mathrm{CaO}-\mathrm{MgO}-\mathrm{Al}_{2} \mathrm{O}_{3}-\mathrm{SiO}_{2}-\mathrm{FeO}$ systems and where melts equilibrate with at least olivine and orthopyroxene. See Table S1 for literature data selection. 

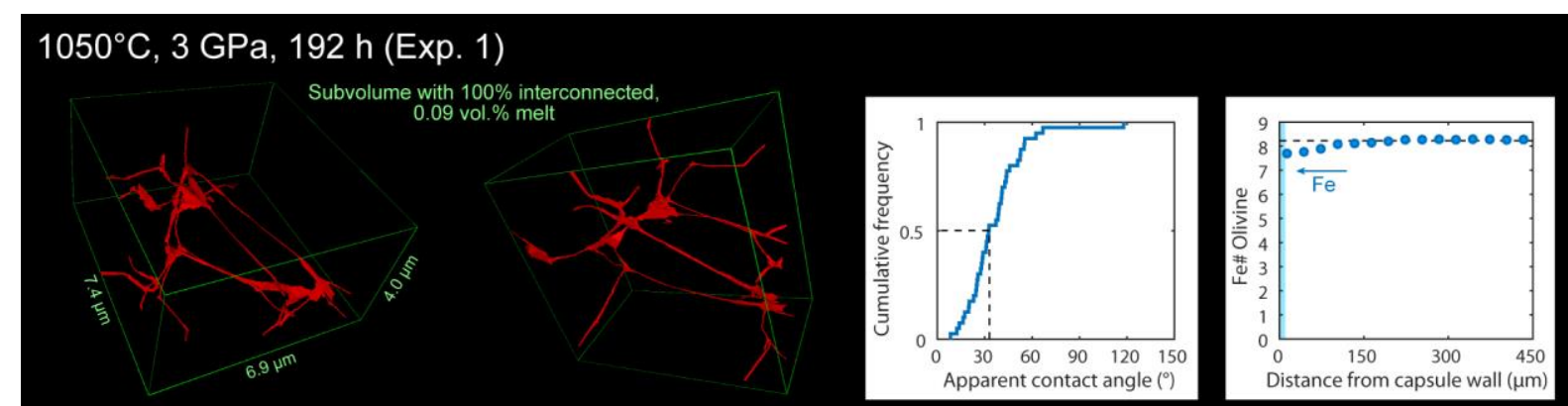

\section{$1200^{\circ} \mathrm{C}, 3 \mathrm{GPa}, 192 \mathrm{~h}($ Exp. 2)}
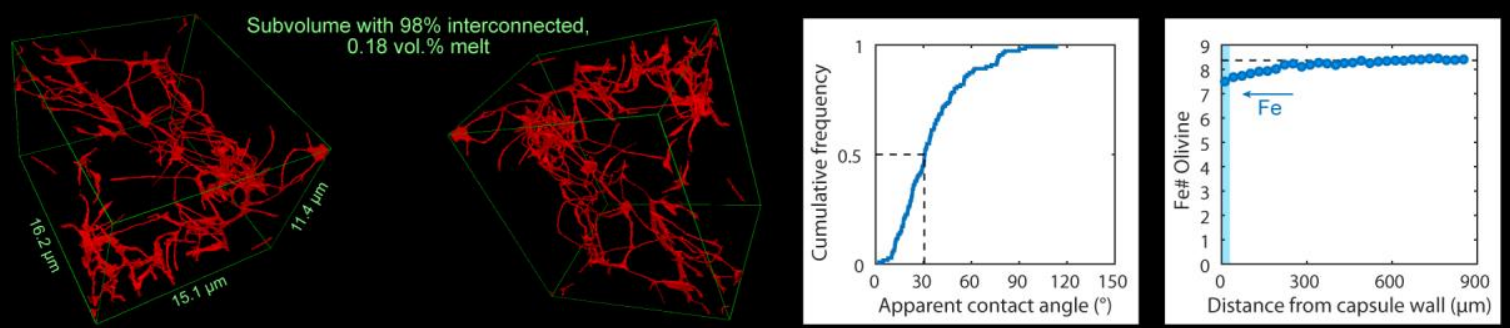

\section{$1327^{\circ} \mathrm{C}, 3 \mathrm{GPa}, 96 \mathrm{~h}($ Exp. 3)}
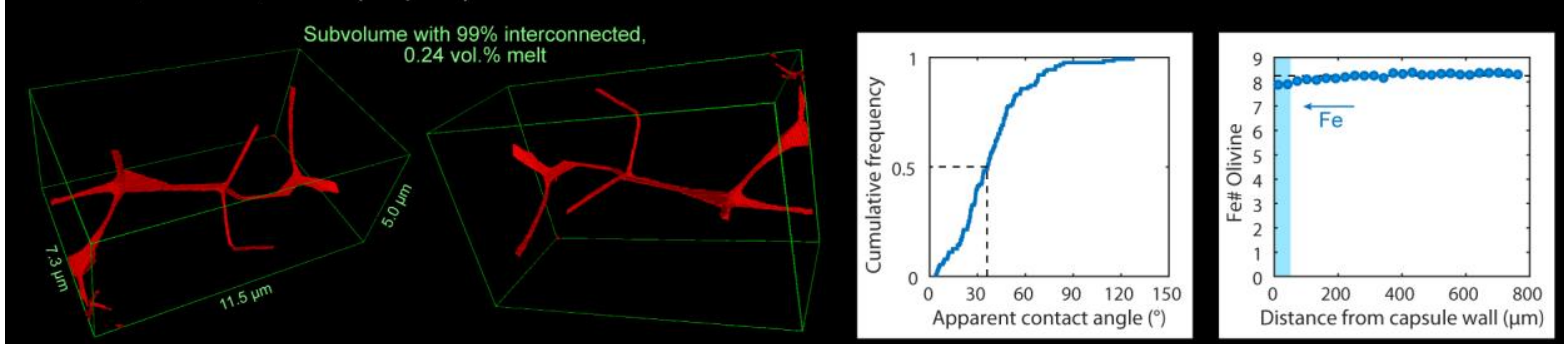

\section{$1360^{\circ} \mathrm{C}, 3 \mathrm{GPa}, 63.5 \mathrm{~h}(\operatorname{Exp} .4)$}
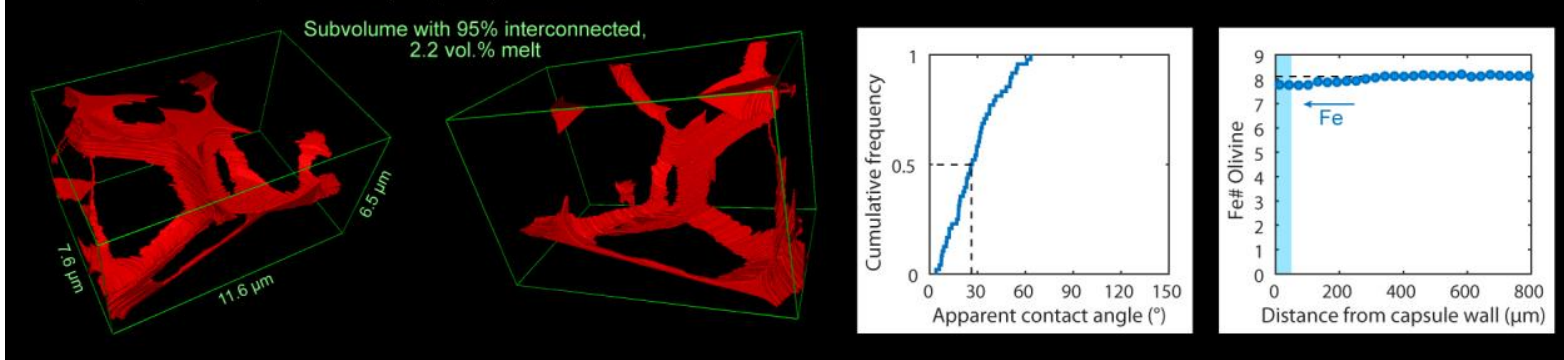

Fig. 5. Interconnection of incipient melts in a $\left(\mathrm{CO}_{2}+\mathrm{H}_{2} \mathrm{O}\right)$-bearing mantle rock experimentally re-equilibrated at shallow mantle temperatures and pressure. $\left(\mathrm{CO}_{2}+\mathrm{H}_{2} \mathrm{O}\right)$-rich melts virtually fully interconnect in the intergranular medium of all samples, from 1.5 vol. $\%$ melt at $1360^{\circ} \mathrm{C}\left(\right.$ Exp. 4) down to 0.11 vol. \% melt at $1050^{\circ} \mathrm{C}$ (Exp. 1). Left panels, high-resolution 3D reconstructions reveal virtually fully interconnected melt networks (rotations of the volumes are available as Videos S1-S4). Middle right panels, cumulative distributions of apparent contact angles at the junctions of incipient melts with the various mineral phases of the samples. Median contact angles are about $30^{\circ}$ in all samples, i.e. much less than the $60^{\circ}$ threshold below which aggregates are reported as pale blue areas (see Supplementary Material). 


\subsection{Predominance of interconnected, volatile-rich melts in the LVZ}

247 Our experiments directly evidence incipient melting where minute amounts of both $\mathrm{CO}_{2}$ and $\mathrm{H}_{2} \mathrm{O}$ 248 generate minute amounts of $\left(\mathrm{CO}_{2}+\mathrm{H}_{2} \mathrm{O}\right)$-rich melts in mantle rocks down to lithosphere temperatures

249 (Figs. 2-4). They corroborate studies that have long predicted this phenomenon from volatile-doped experiments at much higher melt fractions (Wallace and Green, 1988; Hirshmann, 2010; Dasgupta et al., 2013; Massuyeau et al., 2015; Gaillard et al., 2019) (Figs. 1, 4). Note that, although our experiments

252 were performed at $3 \mathrm{GPa}$, volatile-assisted melting was also observed at much lower and much higher pressures covering the range of LVZ pressures (see e.g. Massuyeau et al., 2015 and references therein). Hence, incipient melting occurs in the largest part of the oceanic mantle, generating minute amounts of melt highly enriched in both $\mathrm{CO}_{2}$ and $\mathrm{H}_{2} \mathrm{O}$ and depleted in $\mathrm{SiO}_{2}$ (e.g. Exp. 1 to 3 from 1050 to $1327^{\circ} \mathrm{C}$ ). At the vicinity of hot settings like ridges or hotspots, melt fraction and $\mathrm{SiO}_{2}$ content increase while volatile content dilutes as temperature enhances silicate melting (e.g. Exp. 4 at $1360^{\circ} \mathrm{C}$ ).

As volatile content is very low and highly heterogeneously distributed in the upper mantle (Le Voyer et al., 2017), the question of melt interconnection in highly volatile-depleted mantle regions with extremely low melt fraction arises. Interconnection is found invariably complete down to the $\sim 0.1$ vol. $\%$ volatilerich melt produced in our experiments, with no evidence of deterioration (Fig. 5). This is confirmed by the $\sim 30^{\circ}$ contact angle of partially molten mantle rock in the $\left(\mathrm{CO}_{2}+\mathrm{H}_{2} \mathrm{O}\right)$-assisted melting domain which is significantly smaller than the $60^{\circ}$ threshold below which interconnection occurs at any melt fraction (von Bargen and Waff, 1986) (Fig. 5).

The persistence of interconnection at extremely low melt fractions was also observed in experiments in simplified petrological systems and at higher temperatures. The smallest silicate melt fraction in monomineralic olivine aggregate ever investigated, i.e. $\sim 0.01$ vol. $\%$, was found to be interconnected at $1200^{\circ} \mathrm{C}$ and $0.2 \mathrm{GPa}$ (Faul et al., 2004). Minarik and Watson (1995) investigated bulk mass transport as a function of Na-carbonate melt fractions in monomineralic olivine aggregates at $1300^{\circ} \mathrm{C}$ and $1 \mathrm{GPa}$, and reported transport enhancements down to $\sim 0.007$ vol. $\%$ melt. The absence of detection of mass 
transport enhancement at lower melt fractions does not imply that melt interconnection stops, but that the enhancement could be too weak to be distinguished from mass transport in melt-free sample. It should be noted that Minarik and Watson (1995) inferred an interconnection cut-off at $\sim 0.07$ vol.\% from their longest experiments $(\sim 100 \mathrm{~h})$. However these conclusions were very likely misled by a loss of melt to the surrounding graphite medium in the longest experiments given the extremely fast migration of Na-carbonate in olivine aggregates (Hammouda and Laporte, 2000). Laumonier et al. (2017) investigated the electrical conductivity of mixtures of monomineralic olivine aggregate with silicate melt and reported conductivity enhancement already at the smallest added melt fraction, i.e. 0.15 vol.\%. The 0.5 vol.\% threshold pointed by Laumonier et al. (2017) thus does not represent a connection threshold, but might rather be related to an evolution of melt geometry such as the increase in grain boundary wetness observed between our samples with $\sim 0.1-0.15$ vol.\% melt (Exp. 1-3) and with 1.5 vol.\% melt (Exp. 4) (Fig. 5, Table 2).

Melt thus form interconnected networks down to extremely low melt fractions, without evidence for any interconnection threshold, as predicted for systems with contact angles below $60^{\circ}$ (von Bargen and Waff, 1986). Melt interconnection is also predicted to be independent on grain size (von Bargen and Waff, 1986), being micrometric as in experiments or millimetric as in the mantle. Note that, aside from melt interconnection, melt mobility should be enhanced at large mantle grain size as it implies melt channels with larger cross-sectional areas, and thus smaller surface-to-volume ratio, favouring buoyancy over capillarity (von Bargen and Waff, 1986; Holtzman, 2016). It is also worth noticing that melt interconnection has been reported over the range of LVZ pressures, in experiments from e.g. 0.2 GPa (Faul et al., 2004) to $7 \mathrm{GPa}$ (Yoshino et al., 2009). Therefore, interconnected, volatile-rich melts should prevail in the mantle, in both the asthenosphere and the lithosphere, down to the coldest temperatures of the $\left(\mathrm{CO}_{2}+\mathrm{H}_{2} \mathrm{O}\right)$-assisted melting domain, and in highly volatile-depleted regions.

\subsection{Correspondence of geophysical anomalies and volatile-assisted melting in the LVZ}

The nature of the low velocity zone (LVZ) in oceanic mantle can be reassessed in light of our findings. Sharp drops in shear wave velocity (Vs) are detected using SS precursors in the shallow mantle beneath Pacific, with Vs lowering ranging from 3 to 22\% (Rychert and Shearer, 2011; Schmerr, 2012; 
Tharimena et al., 2017). The top of these seismic anomalies locates at 30-80 km depth and only slightly deepens as a function of lithosphere age (Fig. 6). The onset of increase in Vs radial anisotropy in Pacific locates at similar depths (Burgos et al., 2014), and also only slightly deepens with age (Fig. 6). Moreover, though scarcer than seismic data, very high electrical conductivities $>0.1 \mathrm{~S} / \mathrm{m}$ were detected at similar depths, such as locally beneath the edge of the Cocos plate at 45-70 km depth (Naif et al., 2013) (Fig. 6). The top of these anomalies was referred to as the Gutenberg discontinuity (G) (e.g. Kawakatsu et al., 2009; Schmerr, 2012). Comparison with model of the thermal structure of oceanic mantle (G13R1350 model with $1350^{\circ} \mathrm{C}$ potential temperature from Grose and Afonso, 2013) evidences that the G-discontinuity locates at depths where temperature can be as low as $\sim 950^{\circ} \mathrm{C}$, within the lithosphere (Fig. 6). Actually, the depth of the G-discontinuity, together with its slight deepening with age, is in remarkable agreement with the $\left(\mathrm{CO}_{2}+\mathrm{H}_{2} \mathrm{O}\right)$-assisted melting curve (Wallace and Green, 1988; Sifré et al., 2014) (Fig.6). Since both $\mathrm{CO}_{2}$ and $\mathrm{H}_{2} \mathrm{O}$ are sampled in the mantle (Le Voyer et al., 2017) and since we show here they induce fully interconnected volatile-rich melts, this spatial correspondence evidences that the G-discontinuity delimits the top of a volatile-assisted melting zone.

It is worth recalling that the hydration of olivine is unable to produce such strong anomalies in both seismic velocities (Cline et al., 2018) and electrical conductivities (Gardés et al., 2014, 2015). Temperature excess can enhance partial melting but it appears to be of second order compared to volatile content. Temperature anomalies would not generate sharp discontinuities such as G-discontinuity (Kawakatsu et al., 2009) and would not yield a spatial correlation of G-discontinuity with the $\left(\mathrm{CO}_{2}+\mathrm{H}_{2} \mathrm{O}\right)$-solidus (Fig. 6). Moreover, in a mantle with average volatile content of 140 wt. ppm $\mathrm{CO}_{2}$ and 240 wt.ppm $\mathrm{H}_{2} \mathrm{O}$ (Le Voyer et al., 2017), reproducing the $\sim 0.2 \mathrm{~S} / \mathrm{m}$ electrical conductivities at 45 $70 \mathrm{~km}$ depths in the $\sim 25 \mathrm{Ma}$ lithosphere reported by Naif et al. (2013) would require a partially molten mantle with temperatures above $1550^{\circ} \mathrm{C}$ (Sifré et al., 2014), while temperatures are expected to be 1100 $1300^{\circ} \mathrm{C}$ in this setting (Grose et Afonso, 2013; Fig. 6). On the other hand, those high electrical conductivities can be reached at temperatures around $1200^{\circ} \mathrm{C}$ in a partially molten mantle enriched by 3-4 times the average volatile content (Sifré et al., 2014). 
Although sharp Vs drops mainly distributes at G-discontinuity, they are also found down to $\sim 180 \mathrm{~km}$ depth beneath Pacific (Fig. 6). Experimental petrology predicts that the decrease of oxygen fugacity as a function of depth in the upper mantle should limit the range of stability of oxidised forms of carbon, and thus $\mathrm{CO}_{2}$-bearing melts. Estimations for this redox freezing boundary (RFB) range between 150 and $250 \mathrm{~km}$ depth (Stagno and Frost, 2010; Rohrbach and Schmidt, 2011), in line with the $180 \mathrm{~km}$ depth below which no more sharp Vs drops are observed. The distribution of sharp Vs drops thus coincides with a melting zone, which extends from G-discontinuity in the lithosphere, i.e. at the location of the $\left(\mathrm{CO}_{2}+\mathrm{H}_{2} \mathrm{O}\right)$-solidus, down to the RFB in the asthenosphere beneath the whole Pacific basin (Fig. 6). It is worth noticing that such a spatial extent can only result from $\left(\mathrm{CO}_{2}+\mathrm{H}_{2} \mathrm{O}\right)$-assisted melting. Volatilefree-melting and $\mathrm{H}_{2} \mathrm{O}$-only-assisted melting are not possible at high depth or beneath mature to old lithosphere (Figs. 1, 6), and they are irrelevant since both $\mathrm{CO}_{2}$ and $\mathrm{H}_{2} \mathrm{O}$ are detected in the mantle (Le Voyer et al., 2017).

4.3 Low and heterogeneous distribution of volatile-rich melt imaged by geophysical surveys in the LVZ

The debate on the origin of the LVZ long opposed solid state mechanisms (e.g. Hirth and Kohlstedt, 1996; Preistley and McKenzie, 2013; Takei, 2017; Karato and Park, 2019) and partial melting (e.g. Hirshmann, 2010; Schmerr, 2012; Dasgupta et al., 2013; Naif et al., 2013; Sifré et al., 2014; Chantel et al., 2016; Holtzman, 2016; Gaillard et al., 2019). Nevertheless, the magnitude of geophysical signals from the LVZ must result from the combination of both phenomena, with respective contributions depending on melt fraction. Apart from the strong, local geophysical anomalies discussed above, most of the locations investigated by Schmerr (2012) do not yield measurable sharp drops in shear wave velocity using SS precursors. Moreover, negligible amount of melt is required to account for the electrical conductivity beneath the mature lithosphere at NoMelt area in Pacific (Sarafian et al., 2015). Away from hot settings such as ridges or hotspot, the smooth evolution of global-scale Vs to its minimum at $\sim 150 \mathrm{~km}$ depth (Fig. 6) is compatible with the response of solid mantle rocks to the changes of temperature and pressure in the LVZ (Preistley and McKenzie, 2013; Takei, 2017). This indicates that, on average, melt content is very low in the mantle. 
This is consistent with the very low volatile contents reported by geochemical surveys, with average values estimated at $\sim 140$ wt.ppm $\mathrm{CO}_{2}$ and $\sim 240$ wt.ppm $\mathrm{H}_{2} \mathrm{O}$ (Le Voyer et al., 2017). These values are $\sim 3$ times less than in present experiments where incipient melting of mantle rock with $\sim 500$ wt.ppm $\mathrm{CO}_{2}$ and $\sim 630$ wt.ppm $\mathrm{H}_{2} \mathrm{O}$ bulk content induced $\sim 0.1-0.15$ vol. $\%$ melt. This yields an average melt fraction of 0.03-0.05 vol.\% in the upper mantle. In absence of measurement of Vs as a function of small fractions of $\left(\mathrm{CO}_{2}+\mathrm{H}_{2} \mathrm{O}\right)$-rich melts, one can tentatively estimate a threshold for local, sharp Vs drops detection from Vs measurements on olivine aggregates mixed with basaltic melt by Chantel et al. (2016). Note that the similar $\sim 30^{\circ}$ contact angles for the $\left(\mathrm{CO}_{2}+\mathrm{H}_{2} \mathrm{O}\right)$-rich melts measured here indicate a comparable interconnection geometry with basaltic melts (von Bargen and Waff, 1986). The detection of sharp Vs drops over less than $\sim 5 \mathrm{~km}$ using SS precursors requires Vs lowering by at least $\sim 2 \%$ according to Schmerr (2012). This requires a melt fraction of at least $\sim 0.1$ vol.\% according to Chantel et al. (2016). The $\sim 0.03-0.05$ vol.\% average melt fraction in the mantle is thus below threshold for sharp Vs drops detection using SS precursors, and consistent with mainly unaffecting global-scale geophysical signals (Preistley and McKenzie, 2013; Takei, 2017) (Fig. 6). Nevertheless, geochemical surveys evidence that mantle volatiles distribution is highly heterogeneous, and volatile contents reported above are averages from highly dispersed values (Le Voyer et al., 2017). The local detections of sharp Vs lowering of $\sim 3$ to $22 \%$ using SS precursors (Rychert and Shearer, 2011; Schmerr, 2012; Tharimena et al., 2017) are thus in line with a mantle with local melt enrichments, corresponding to regions with $\sim 0.2$ to 1.5 vol.\% melt according to Chantel et al. (2016) (see their preferred curve at anelasticity attenuation factor $\alpha=0.26$ in their Fig. 3). These values fall in the range of melt fractions produced in our experiments (Table 2), indicating local volatile enrichments in the mantle of more than $\sim 3$ times the average mantle content. 


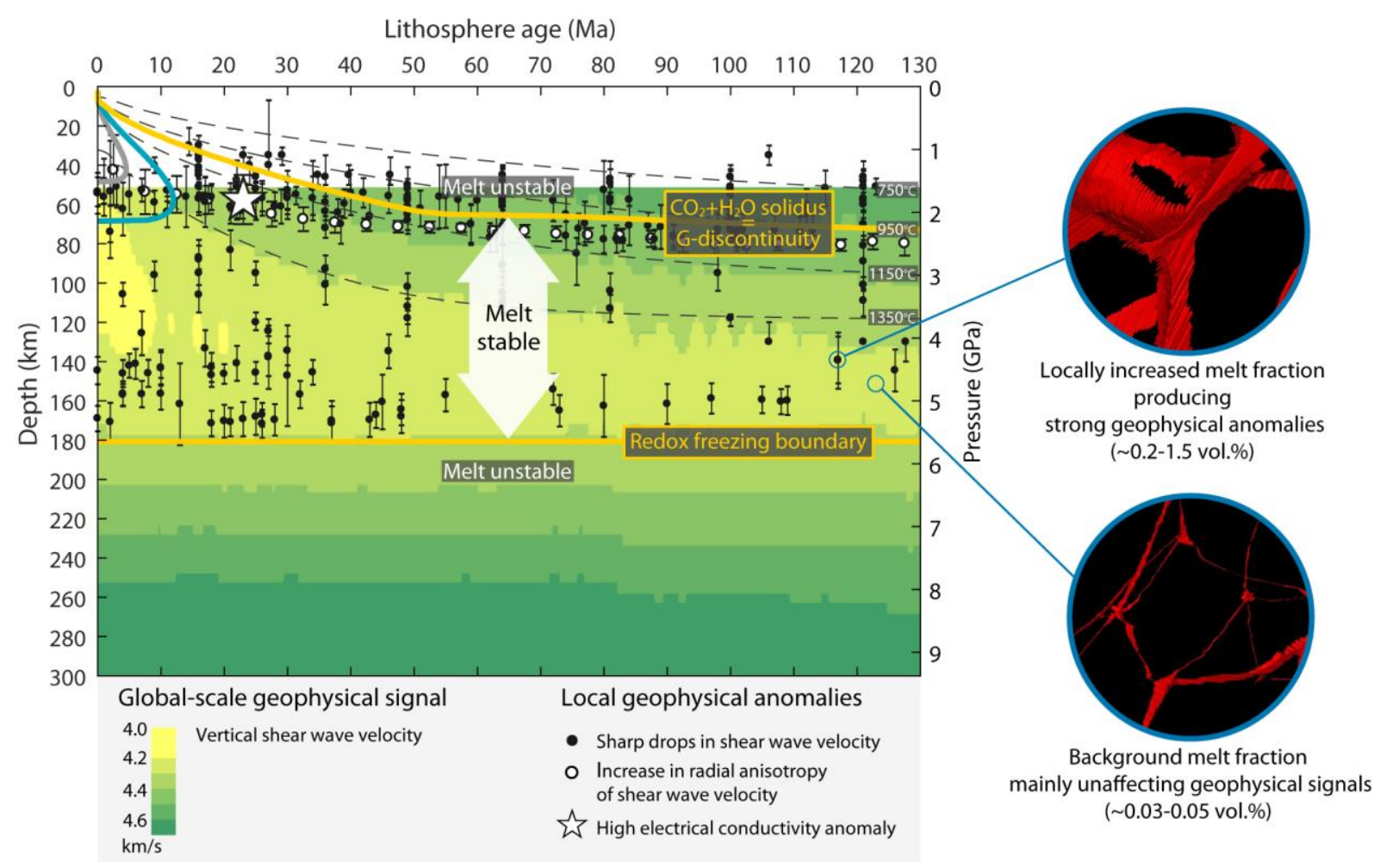

Fig. 6. Correspondence of volatile-assisted melting domain and geophysical anomalies domain in the LVZ of Pacific upper mantle. Apart from ridge, global-scale shear wave velocity is mainly unaffected by incipient, interconnected melt because of a too low background melt fraction, estimated at $\sim 0.03-0.05$ vol.\%. Sporadic, localized geophysical anomalies arise from areas with increased melt fractions, estimated to range from $\sim 0.2$ to $\sim 1.5$ vol.\% for the detection of sharp Vs drops using SS precursors. These anomalies lay in the stability domain of $\left(\mathrm{CO}_{2}+\mathrm{H}_{2} \mathrm{O}\right)$-assisted melting. This domain extends beneath the whole ocean basin, and is delimited at its top by the $\left(\mathrm{CO}_{2}+\mathrm{H}_{2} \mathrm{O}\right)$-solidus (Wallace and Green, 1988), which coincides with Gdiscontinuity, and at its bottom by the redox freezing boundary at $\sim 180 \mathrm{~km}$ depth, in the range of petrological estimations (150250 km; Stagno and Frost, 2010; Rohrbach and Schmidt, 2011). Volatile-free-melting (grey curve) and $\mathrm{H}_{2} \mathrm{O}$-only-assisted melting (blue curve) domains (Sarafian et al., 2017) are restricted to the vicinity of ridge. Note that the G-discontinuity locates at depths where temperature can be as low as $\sim 950^{\circ} \mathrm{C}$, within the lithosphere. Vertical shear wave velocity contours are PM_v2_2012 tomographic model from Preistley and McKenzie (2013). Sharp drops in shear wave velocity obtained from SS precursors are from Rychert and Shearer (2011), Schmerr (2012) and Tharimena et al. (2017). Increase in radial anisotropy of shear wave velocity is from Burgos et al. (2014). High electrical conductivity anomaly is from Naif et al. (2013). Mantle thermal structure is G13R1350 model with $1350^{\circ} \mathrm{C}$ potential temperature from Grose and Afonso (2013). The illustrations of grain scale melt interconnection at increased and background melt fractions are based on the 3D imaging of our samples (not to scale). 
Geophysical surveys thus appears to image in situ the very low and highly heterogeneous distribution of melt in the mantle corresponding to the very low and highly heterogeneous distribution of volatiles reported by surficial geochemical surveys. While partial melts are probably ubiquitous and must interconnect in the LVZ, the global-scale geophysical signature of the LVZ mainly derives from solid state processes because the background melt fraction corresponding to mantle average volatile content is very low, being $\sim 0.03-0.05$ vol.\% melt for 140 wt.ppm $\mathrm{CO}_{2}$ and 240 wt.ppm $\mathrm{H}_{2} \mathrm{O}$ (Fig. 6). Enhanced signals arise from sporadic, localized areas where melt fraction is increased (Fig. 6), e.g. above $\sim 0.2$ vol.\% melt for detecting sharp Vs drops using SS precursors which corresponds to mantle volatile enrichments above $\sim 500$ wt.ppm of both $\mathrm{CO}_{2}$ and $\mathrm{H}_{2} \mathrm{O}$. Geophysical surveys also appear to reveal the dynamics of melt redistribution and localization in the LVZ. This is most striking at G-discontinuity where the concentration of geophysical anomalies suggests a zone of melt accumulation, though heterogeneous and likely corresponding to an average melt fraction well below 1 vol.\%. One might speculate that volatile-rich melts generated from the asthenosphere migrate upwards to the lithosphere by percolation via interconnected networks and/or mantle convection (Rabinowicz et al., 2002). They are slowed down at G-discontinuity, i.e. at $\left(\mathrm{CO}_{2}+\mathrm{H}_{2} \mathrm{O}\right)$-solidus, above which they must solidify, unless local setting allows for fast, out of equilibrium transfer to shallower depths (Hirano et al., 2006; Machida et al., 2017).

In-depth deciphering of the dynamics of melt and volatiles in the LVZ calls for investigations on the seismic velocity, permeability and rheology of partially molten mantle rocks covering the diversity of mantle melt compositions, fractions and temperatures. This is also critical for deciphering Earth's global dynamics. If small fractions of volatile-rich melts significantly lower the viscosity of mantle rocks (Hirth and Kohlstedt 1995a, 1995b, 2003; Takei and Holtzman, 2009a, 2009b; Holtzman, 2016), the LVZ could be a weakening zone between the rigid lithospheric plates and the convective mantle, playing key role in plate tectonics. 


\section{Conclusion}

419

(i) We experimentally evidence the long predicted incipient melting regime where minute amounts of both $\mathrm{CO}_{2}$ and $\mathrm{H}_{2} \mathrm{O}$ generate minute amounts of $\left(\mathrm{CO}_{2}+\mathrm{H}_{2} \mathrm{O}\right)$-rich melts in mantle rocks down to the coldest temperatures of the $\left(\mathrm{CO}_{2}+\mathrm{H}_{2} \mathrm{O}\right)$-assisted melting domain, i.e. in both the asthenosphere and the lithosphere.

(ii) We experimentally evidence that those minute amounts of volatile-rich melts do interconnect in mantle rocks, enabling thus the modification of geophysical signals from the mantle. No interconnection threshold can be evidenced or predicted. Interconnection of volatile-rich melts must prevail even at extremely low melt fractions in highly volatile-depleted regions of the mantle.

(iii) The distribution of geophysical anomalies in the oceanic mantle corresponds to a melting zone which extends from the $\left(\mathrm{CO}_{2}+\mathrm{H}_{2} \mathrm{O}\right)$-solidus at $\sim 30-80 \mathrm{~km}$ depth in the lithosphere, corresponding to Gutenberg discontinuity, down to the redox freezing boundary in the asthenosphere at $\sim 180 \mathrm{~km}$ depth. G-discontinuity locates at depths where temperature can be as low as $\sim 950^{\circ} \mathrm{C}$, within the lithosphere.

(iv) Geophysical surveys appears to image in situ the very low and highly heterogeneous distribution of melt in the mantle generated by the very low and highly heterogeneous distribution of volatiles probed by surficial geochemical surveys. The global-scale geophysical signature of the LVZ appears mainly unaffected because the average background melt fraction is very low, estimated at $\sim 0.03-0.05$ vol.\% melt. Nevertheless, enhanced geophysical signals arise from sporadic, localized areas where melt fraction is above a threshold, estimated at $\sim 0.2$ vol. $\%$ melt for sharp Vs drop detection using SS precursors. 


\section{References}

444 Burgos, G., Montagner, J. P., Beucler, E., Capdeville, Y., Mocquet, A., Drilleau, M., 2014. Oceanic 445 lithosphere/asthenosphere boundary from surface wave dispersion data. J. Geophys. Res. Solid Earth 119, 1079-1093.

447

Chantel, J., Manthilake, G., Andrault, D., Novella, D., Yu, T., Wang, Y., 2016. Experimental evidence supports mantle partial melting in the asthenosphere. Sci. Adv. 2, e1600246.

Cline, C. J., Faul, U. H., David, E. C., Berry, A. C., Jackson, I., 2018. Redox-influenced seismic properties of upper-mantle olivine. Nature 555, 355-358.

Cocoo, A. P., Nelson, G. J., Harris, W. M., Hakajo, A., Myles, T. D., Kiss, A. M., Lombardo, J. J., Chiu, W. K. S., 2013. Three-dimensional microstructural imaging methods for energy materials. Phys. Chem. Chem. Phys. 15, 16377.

Dasgupta, R., Mallik, A., Tsuno, K., Withers, A. C., Hirth, G., Hirschmann, M. M., 2013. Carbondioxide-rich silicate melt in the Earth's upper mantle. Nature 493, 211-215.

Faul, U. H., Fitz Gerald, J. D., Jackson, I., 2004. Shear wave attenuation and dispersion in melt-bearing olivine polycrystals: 2. Microstructural interpretation and seismological implications. J. Geophys. Res. 109, B06202.

Gaillard, F., Sator, N., Gardés, E., Guillot, B., Massuyeau, M., Sifré, D., Hammouda, T., Richard, G., 2019. The Link between the Physical and Chemical Properties of Carbon-Bearing Melts and Their Application for Geophysical Imaging of Earth's Mantle. In Orcutt, B., Daniel, I., Dasgupta, R. (Eds.), Deep Carbon: Past to Present, pp. 163-187. Cambridge University Press.

Gardés, E., Gaillard, F., Tarits, P., 2014. Toward a unified hydrous olivine electrical conductivity law. Geochem. Geophys. Geosyst. 15, 4984-5000.

Gardés, E., Gaillard, F., Tarits, P., 2015. Comment to "High and highly anisotropic electrical conductivity of the asthenosphere due to hydrogen diffusion in olivine" by Dai and Karato [Earth Planet. Sci. Lett. 408 (2014) 79-86]. Earth Planet. Sci. Lett. 427, 296-299.Grose, C. J., Afonso, J. 

C., 2013. Comprehensive plate models for the thermal evolution of oceanic lithosphere. Geochem. Geophys. Geosyst. 14, 3751-3778.

Hammouda, T., Laporte, D., 2000. Ultrafast mantle impregnation by carbonatite melts. Geology 28, $283-285$.

Hirano, N., Takahashi, E., Yamamoto, J., Abe, N., Ingle, S. P., Kaneoka, I., Hirata, T., Kimura, J. I., Ishii, T., Ogawa, Y., Machida, S., Suyehiro, K., 2006. Volcanism in Response to Plate Flexure. Science 313, 1426-1428.

Hirschmann, M.M., 2010. Partial melt in the oceanic low velocity zone. Phys. Earth Planet. Inter. 179, $60-71$

Hirth, G., Kohlstedt, D. L., 1995a. Experimental constraints on the dynamics of the partially molten upper mantle: Deformation in the diffusion creep regime. J. Geophys. Res. 100, 1981-2001.

Hirth, G., Kohlstedt, D. L., 1995b. Experimental constraints on the dynamics of the partially molten upper mantle 2. Deformation in the dislocation creep regime. J. Geophys. Res. 100, 15441-15449.

Hirth, G., Kohlstedt, D. L., 1996. Water in the oceanic upper mantle: Implications for rheology, melt extraction and the evolution of the lithosphere. Earth Planet. Sci. Lett. 144, 93-108.

Hirth, G., Kohlstedt, D. L., 2003. Rheology of the upper mantle and the mantle wedge: a view from the experimentalists. In: Eiler, J. (Ed.). Inside the subduction factory, Geophysical Monograph vol. 138, pp. 83-105. AGU.

Holtzman, B. K., 2016. Questions on the existence, persistence, and mechanical effects of a very small melt fraction in the asthenosphere. Geochem. Geophys. Geosyst. 17, 470-484.

Karato, S. I., Park, J., 2019. On the Origin of the Upper Mantle Seismic Discontinuities. In: Yuan, H., Romanowicz, B. (Eds.). Lithospheric Discontinuities, Geophysical Monograph vol. 239, pp. 5-34. AGU \& Wiley. 
Kawakatsu, H., Kumar, P., Takei, Y., Shinohara, M., Kanazawa, T., Araki, E., Suyehiro, K, 2009. Seismic Evidence for Sharp Lithosphere-Asthenosphere Boundaries of Oceanic Plates. Science 324, $499-502$.

Laporte, D., Watson, E. B., 1995. Experimental and theoretical constraints on melt distribution in crustal sources: the effect of crystalline anisotropy on melt interconnectivity. Chem. Geol. 124, 161-184.

Laumonier, M., Farla, R., Frost, D. J., Katsura, T., Marquardt, K., Bouvier, A. S., Baumgartner, L. P., 2017. Experimental determination of melt interconnectivity and electrical conductivity in the upper mantle. Earth Planet. Sci. Lett. 463, 286-297.

Le Voyer, M., Kelley, K. A., Cottrell, E., Hauri, E. H., 2017. Heterogeneity in mantle carbon content from $\mathrm{CO}_{2}$-undersaturated basalts. Nat. Commun. 8, 14062.

Machida, S., Kogiso, T., Hirano, N., 2017. Petit-spot as definitive evidence for partial melting in the asthenosphere caused by $\mathrm{CO}_{2}$. Nat. Commun. 8, 14302.

Massuyeau, M., Gardés, E., Morizet, Y., Gaillard, F., 2015. A model for the activity of silica along the carbonatite-kimberlite-mellilitite-basanite melt compositional joint. Chem. Geol. 418, 206-216.

Miller, K. J., Zhu, W., Montési, L. G. J., Gaetani, G. A., 2014. Experimental quantification of permeability of partially molten mantle rock. Earth Planet. Sci. Lett. 388, 273-282.

Minarik, W., Watson, E. B., 1995. Interconnectivity of carbonate melt at low melt fraction. Earth Planet. Sci. Lett. 133, 423-437.

Mu, S., Faul, U. H., 2016. Grain boundary wetness of partially molten dunite. Contrib. Mineral. Petrol. $171,40$.

Naif, S., Key, K, Constable, S., Evans, R. L., 2013. Melt-rich channel observed at the lithosphereasthenosphere boundary. Nature 495, 356-359.

Preistley, K., McKenzie, D., 2013. The relationship between shear wave velocity, temperature, attenuation and viscosity in the shallow part of the mantle. Earth Planet. Sci. Lett. 381, 78-91. 
Rabinowicz, M., Ricard, Y., Grégoire, M., 2002. Compaction in a mantle with a very small melt concentration: Implications for the generation of carbonatitic and carbonate-bearing high alkaline mafic melt impregnations. Earth Planet. Sci. Lett. 203, 205-220.

Rohrbach, A., Schmidt, M. W., 2011. Redox freezing and melting in the Earth's deep mantle resulting from carbon-iron redox coupling. Nature 472, 209-212.

Rychert, C. A., Shearer, P., 2011. Imaging the lithosphere-asthenosphere boundary beneath the Pacific using SS waveform modelling. J. Geophys. Res. 116, B07307.

Sarafian, E., Evans, R. L., Collins, J. A., Elsenbeck, J., Gaetani, G. A., Gaherty, J. B., Hirth, G., Lizarralde, D., 2015. The electrical structure of the central Pacific upper mantle constrained by the NoMelt experiment. Geochem. Geophys. Geosyst. 16, 1115-1132.

Sarafian, E., Gaetani, G. A., Hauri, E. H., Sarafian, A. R., 2017. Experimental constraints on the damp peridotite solidus and oceanic mantle potential temperature. Science 355, 942-945.

Schindelin, J., Arganda-Carreras, I., Frise, E., Kaynig, V., Longair, M., Pietzsch, T., Preibisch, S., Rueden, C., Saafeld, S., Schmid, B., Tinevez, J. Y., White, D. J., Hartenstein, V., Eliceri, K., Tomancak, P., Cardona, A., 2012. Fiji: an open-source platform for biological-image analysis. Nature Methods 9, 676-682.

Schmerr, N., 2012. The Gutenberg Discontinuity: Melt at the Lithosphere-Asthenosphere Boundary. Science 335, 1480-1483.

Sifré, D., Gardés, E., Massuyeau, M., Hashim, L., Hier-Majumder, S., Gaillard, F., 2014. Electrical conductivity during incipient melting in the oceanic low-velocity zone. Nature 509, 81-85.

Stagno, V., Frost, D. J., 2010. Carbon speciation in the asthenosphere: Experimental measurements of the redox conditions at which carbonate-bearing melts coexist with graphite or diamond in peridotite assemblages. Earth Planet. Sci. Lett. 300, 72-84. 
Takei, Y., Holtzman, B. K., 2009a. Viscous constitutive relations of solid-liquid composites in terms of grain boundary contiguity: 1. Grain boundary diffusion control model. J. Geophys. Res. 114, B06205.

Takei, Y., Holtzman, B. K., 2009b. Viscous constitutive relations of solid-liquid composites in terms of grain boundary contiguity: 2. Compositional model for small melt fractions. J. Geophys. Res. 114, B06206.

Takei, Y., 2017. Effects of Partial Melting on Seismic Velocity and Attenuation: A New Insight from Experiments. Annu. Rev. Earth Planet. Sci. 45, 447-70.

ten Grotenhuis, S. M., Drury, M. R., Spiers, C. J., Peach, C.J., 2005. Melt distribution in olivine rocks based on electrical conductivity measurements. J. Geophys. Res. 110, B12201.

Tharimena, S., Rychert, C., Harmon, N., White, P., 2017. Imaging Pacific lithosphere seismic discontinuities-Insights from SS precursor modelling. J. Geophys. Res. Solid Earth 122, 2131-2152.

von Bargen, N., Waff, H. S., 1986. Permeabilities, interfacial areas and curvatures of partially molten systems: Results of numerical computations of equilibrium microstructures. J. Geophys. Res. Solid Earth 91, 9261-9276.

Wallace, M. E., Green, D. H., 1988. An experimental determination of primary carbonatite magma composition. Nature 335, 343-346.

Yoshino, T., Yamazaki, D., Mibe K., 2009. Well-wetted olivine grain boundaries in partially molten peridotite in the asthenosphere. Earth Planet. Sci. Lett. 283, 167-173.

Yoshino, T., Laumonier, M., McIsaac, E., Katsura, T., 2010. Electrical conductivity of basaltic and carbonatite melt-bearing peridotites at high pressures: implications for melt distribution and melt fraction in the upper mantle. Earth Planet. Sci. Lett. 285, 593-602.

Zhu, W., Gaetani, G. A., Fusseis, F., Montési, L. G. J., De Carlo, F., 2011. Microtomography of Partially Molten Rocks: Three-Dimensional Melt Distribution in Mantle Peridotite. Science 332, 88-91. 
564 We are grateful to B. K. Holtzman and an anonymous reviewer for their helpful comments. This work 565 benefited from funding by the French National Research Agency program "Investissements d'avenir" 566 (ANR-11-EQPX-0020) and by the European Research Council (ElectroLith project, ERC project 567 \#279790). M.L. acknowledges the French Government Laboratory of Excellence initiative (ClerVolc, 568 contribution \#357). M.M. acknowledges funding from the Department of Science and Technology 569 Research Chairs Initiative as administered by the South African National Research Foundation (SARChI 570 Chair granted to Fanus Viljoen, grant number \#64779).

571

572 